\title{
INVESTIGATING THE MODIFICATIONS IN PROPERTIES OF CLAYEY SOIL UTILIZING PPC FOR VARIABLE DYNAMIC COMPACTION
}

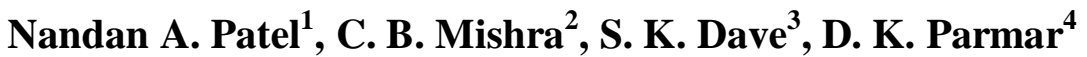 \\ ${ }^{1}$ Student of M. Tech. (Transportation System Engg.), BVM Engineering College, V. V. Nagar, Anand, India \\ ${ }^{2}$ Associate Professor, Civil Engineering Department, BVM Engineering College, V. V. Nagar, Anand, India \\ ${ }^{3}$ Assistant Professor, Applied Mechanical Department, B\& B Institute of Tech., V. V. Nagar, Anand, India \\ ${ }^{4}$ Assistant Professor, Applied Mechanical Department, B\& B Institute of Tech., V. V. Nagar, Anand, India
}

\begin{abstract}
Road improvement is one of the significant parts of developing foundation which is growing at a quick rate; the development of roads is of real concern in India as it elevates access to monetary and social administrations, creating horticultural income and productivity employment. In India the greatest impediment to give a complete system of road framework is the constrained funds accessible to build road by the conventional method. The nearby accessible soil is not satisfactory for supporting the reiteration of high business vehicles on consistent road width results into weakening of roads. Clay soils change fundamentally in volume with change in water substance are the reason for distortions to structures that incurs cost taxpayers several billion rupees every year in the India. This paper manages a research facility examination of soil as CL as per Indian Standard (1498 - 1970). To the untreated soil adjustments utilizing the doses of 1 and $2 \%$ PPC are carried out. At first the tests are directed to focus physical \& engineering properties of natural soil by directing research center tests furthermore to assess the change in properties by the addition of stabilizers to be utilized as a part of pavement design for economy.
\end{abstract}

Keywords: Cement, Soil Stabilization, strength, moisture content.

$* * *$

\section{PREAMBLE}

Long term execution of asphalt structures is fundamentally affected by the dependability of the hidden soils. In situ sub reviews frequently don't give the help obliged attaining to worthy execution under traffic loading and environmental demands to oppose unreasonable perpetual distortion oppose shear and maintain a strategic distance from unnecessary diversion that may bring about exhaustion breaking in overlying layers. Accessible earth materials don't generally meet these necessities and may oblige upgrades to their engineering properties so as to change these reasonable earth materials into viable development materials. Despite the fact that adjustment is a compelling option for enhancing soil properties, the engineering properties got from adjustment shift broadly because of heterogeneity in soil creation, contrasts in micro and macro structure among soils, heterogeneity of geologic stores, and because of contrasts in physical and chemical cooperation's between the dirt and hopeful stabilizers. These varieties require the thought of site-particular treatment choices which must be accepted through testing of soil-stabilizer mixtures.

India is confronted with the colossal test of saving and improving the transportation framework to meet the always expanding stresses because of heavier loads going the distance layers to the hidden soil.
Soil tying added substance expands compaction, builds soil density and expands bearing quality so testing ought to be to quantify these. In this study conventional stabilizers Portland pozzolana cement is utilized which involves calcium-silicates and calcium-aluminates that hydrate to structure cementations items and has been effectively utilized for tying soil particles together, accordingly structuring a hard steady mass.

\section{CONCEPTUAL DISTINCTIONS}

This paper for the most part accentuates on change of soil record properties of clayey utilizing PPC. This infers the accompanying destinations which can be advanced as takes after:

1) Efficient utilization of PCC for stabilization of clayey soil

2) Increase parameters of soil like quality utilizing PCC as a part of different extents to be of valuable to road contractors and pavement designers to accomplish economy.

\section{LITERATURE REVIEW}

Sabry A. Shihata and Zaki A. Baghdadi (2001) in their paper on "Long-term strength and durability of soil cement" sturdiness qualities and compressive quality of soil concrete after delayed introduction to saline ground water. The study was limited to three A-2-4 soils. In the investigation of the results the creators accentuate the usage of compressive 
quality as an able pointer of solidness notwithstanding the routine percent mass misfortune. It was observed that at ahead of schedule age's compacted soil-concrete mixtures keep on gaining quality in spite of introduction to saline water up to around 90 days, then the quality disintegrates. The results additionally demonstrate that with time the lingering compressive quality unites to a certain worth, after which the rate of decay gets to be little. This worth happened at around 270 days for the tried soils. Then again, unconfined compressive quality examples submerged in the saline ground water for up to 6 months kept on gaining quality, in spite of the fact that the addition was moderate past 28 days.

Manasseh Joel and Isaac O. Agbede (2011) study on "Mechanical-Cement Stabilization of Laterite for Use as Flexible Pavement Material" the authors attempted to improve the physical and strength properties of a reddishbrown lateritic soil. 15-60\% of sand by dry weight of laterite was used as a modifier in the stabilization of the laterite with $3-12 \%$ by dry weight of cement. Classification, compaction, California bearing ratio CBR, and unconfined compressive strength tests were carried out on the specimens. The plasticity index decreased from $17 \%$ for untreated laterite to $2.5 \%$ when treated with a combination of $60 \%$ sand $+6 \%$ cement. For the two energy levels of compaction, optimum moisture content OMC was found to increase with an increase in cement content but decreased as the sand content increased. The OMC at the West African standard was energy level was consistently lower than the values obtained at the standard proctor SP energy level, while the corresponding values of maximum dry density were higher at the WAS energy level than the values at the SP energy level. The CBR requirements for base course material were met when laterite was admixed with $45 \%$ sand $+6 \%$ cement and $30 \%$ sand $+6 \%$ cement, and $15 \%$ sand $+6 \%$ cement, $30 \%$ sand $+6 \%$ cement, and $45 \%$ sand $+3 \%$ cement at the SP and WAS energy levels, respectively. It can be concluded that sand enhanced the effective stabilization of Ikpayongo laterite with cement within the maximum cement content specified by the Nigerian code.

Grytansarkar, md.rafiqul Islam, Muhammedalamgir, md.Rokonuzzaman (2012) Study on the Geotechnical Properties of Cement based Composite Fine-grained Soil expresses that the impact of bond on the execution of soil, gathered from Khanjahan Ali Hall at Khulna University of Engineering \& Technology (KUET) in Khulna, Bangladesh. The expansion of bond was found to enhance the engineering properties of accessible soil in settled structures particularly quality, workability, and compaction and compressibility attributes. Subsequently, research center tests, for example, compaction, Atterberg breaking points, unconfined compressive quality, direct shear and solidification tests for diverse rates of bond substance and unique soil examples were performed. These test outcomes demonstrate that the soil can be made lighter which prompts diminish in dry thickness and increment in dampness content and decreased compressibility because of the expansion of bond with the dirt. Other than that the unconfined compressive quality and shear quality of soil can be enhanced with the expansion of $7.5 \%$ of bond substance. Mehdi gharib, Hamidreza Saba, Arashbarazesh (2012) In their exploratory study for distinguishing proof and correlation of plastic index and shrinkage properties of earth soils with the addition of cement that there has been an expanding application of different mud minerals with high plasticity in natural and geotechnical tasks. One of the shortcomings of mud minerals is their shrinkage potential while parching. Authors try to analyze the impact of including cement to soil its shrinkage properties and to contrast it and ordinary soil in Golestan Province. Here, the versatility properties (including liquid limit, plastic limit, shrinkage limit, and plastic index)) of clay soils in the district will be inspected and looked at previously, then after the fact including diverse percentages of cement.

\section{PARENT MATERIALS}

Taking after are the materials which are to be utilized as a part of this study:

\subsection{Soil}

Soil sample were gathered from Nadiad i.e. Ahmedabad to Vadodara NH8, Gujarat from where road is to pass. At first, visual examination shows brown color soil. Samples were air dried and pounded to pass through IS 425 microns strainer and after that oven dried at $110^{\circ} \mathrm{C}$ before testing. When the soil is wet it doesn't get to be dry soon. In like way, when altogether dry, it is not soon wetted and shrinks causing breaks.

\subsection{Cement}

The cement utilized is Portland pozzolanic bond (PPC) utilized for the study was bought from the market with the specific gravity of $3.14 \mathrm{~g} / \mathrm{cc}$. Portland Pozzolana bond is a multi-mineral compound made up of oxides of calcium, silica, alumina and iron. In vicinity of suitable measure of water, PPC hydrates help to settle flocculated earth particles through cementation. In these studies $1 \%$ \& $2 \%$ of Portland pozzolana concrete is utilized with the soil under scrutiny.

\section{SCIENTIFIC EXPERIMENTATIONS}

The first work of the study obliged the development of field test of pavement. Soil grouping is done from designing perspective to discover the suitability of soil for potential upgrades of it is a subgrade for development of pavement.

\subsection{Properties of Clayey Soil with and without} Additive

Engineering use of Atterberg limits, are primary soil properties useful for predicting activity of clay. The test conducted to determine properties are of paramount important to classify the soil. 


\subsubsection{Liquid Limit:}

The percentage moisture content at which a soil changes with decreasing wetness from the liquid to the plastic consistency or with increasing wetness from the plastic to the liquid consistency The values obtained indicates that the material is non critical (LL between 20 - 35) as per IS 1498 -1970 .

\begin{tabular}{|l|l|l|l|}
\hline Sample & CL Soil & $\mathbf{1 \%}$ & $\mathbf{2 \%}$ \\
\hline Moisture Can. No & 30 & 36 & 114 \\
\hline Can.+Wet Weight (gm) & 50.72 & 55.64 & 60.56 \\
\hline $\begin{array}{l}\text { Can + Dry Weight } \\
(\mathrm{gm})\end{array}$ & 43.67 & 50.24 & 56.30 \\
\hline No. of Blows & 25 & 25 & 25 \\
\hline Liquid Limit (\%) & 30.40 & 28.21 & 26 \\
\hline
\end{tabular}

\subsubsection{Plastic Limit:}

The percentage moisture content at which a soil changes with decreasing wetness from the plastic to the semi- solid consistency or with increasing wetness from the semi-solid to the plastic consistency.

\begin{tabular}{|l|l|l|l|}
\hline Sample & CL Soil & $\mathbf{1 \%}$ & $\mathbf{2 \%}$ \\
\hline $\begin{array}{l}\text { Can. + Wet } \\
\text { Weight (gm) }\end{array}$ & 33.40 & 41.42 & 49.45 \\
\hline $\begin{array}{l}\text { Can + Dry Weight } \\
(\mathrm{gm})\end{array}$ & 31.27 & 39.86 & 48.45 \\
\hline PlasticLimit (\%) & 19.43 & 17.73 & 16.05 \\
\hline
\end{tabular}

\subsubsection{Plasticity Index:}

The Plasticity index indicating the magnitude of water content range over which the soil remains plastic and the liquidity index, indicating the nearness of a natural soil to the liquid limit and are particularly useful characteristics of soil. The investigations reveal that the plasticity index is having values lower than 12 hence the material is non critical as per IS $1498-1970$.

\begin{tabular}{|l|l|l|l|}
\hline Plasticity Index & CL Soil & $\mathbf{1 \%}$ & $\mathbf{2 \%}$ \\
\hline$\%$ & 10.47 & 10.48 & 9.95 \\
\hline
\end{tabular}

\subsubsection{Free Swell Index:}

Free swell index that represents the ratio of swelled volume of the soil in water per unit weight of the soil is the simplest parameter to indicate swelling ability of soils. With addition of cement to soil, the results show that holding capacity of water is reduced. The degree of expansion is low and is noncritical as per IS $1498-1970$.

\begin{tabular}{|l|l|l|l|}
\hline Sample & $\begin{array}{l}\text { CL } \\
\text { Soil }\end{array}$ & $\mathbf{1 \%}$ & $\mathbf{2 \%}$ \\
\hline Mass of Dry Soil & 10 & 10 & 10 \\
\hline $\begin{array}{l}\text { Volume of Soil in } \\
\text { Water }\end{array}$ & 11.75 & 11.70 & 11.68 \\
\hline $\begin{array}{l}\text { Volume of Soil in } \\
\text { Kerosene }\end{array}$ & 10 & 10.1 & 10.1 \\
\hline Free Swell Index (\%) & 17.50 & 17 & 16.80 \\
\hline
\end{tabular}

\subsubsection{Water Content - Dry Density Relation Using Heavy Compaction}

\section{MDD v/s OMC}

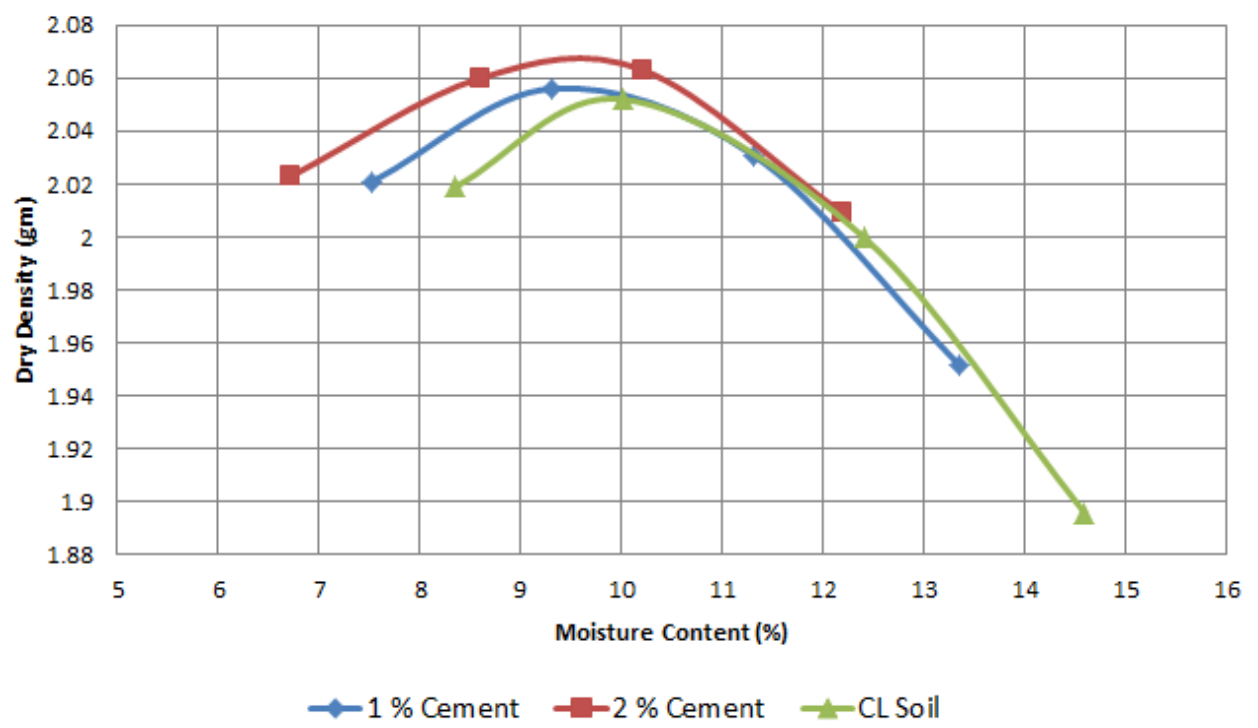




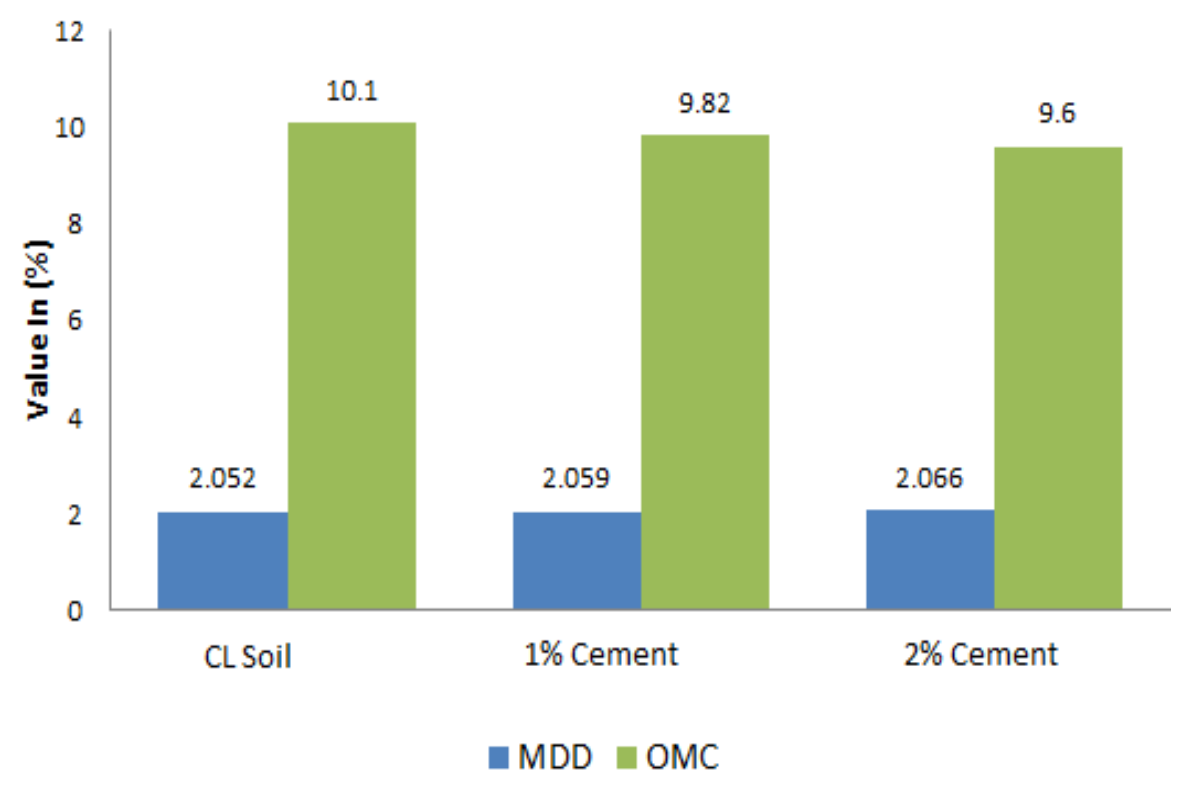

\subsubsection{CBR under Dynamic Compaction}

\subsubsection{CBR value for 10 Blows}

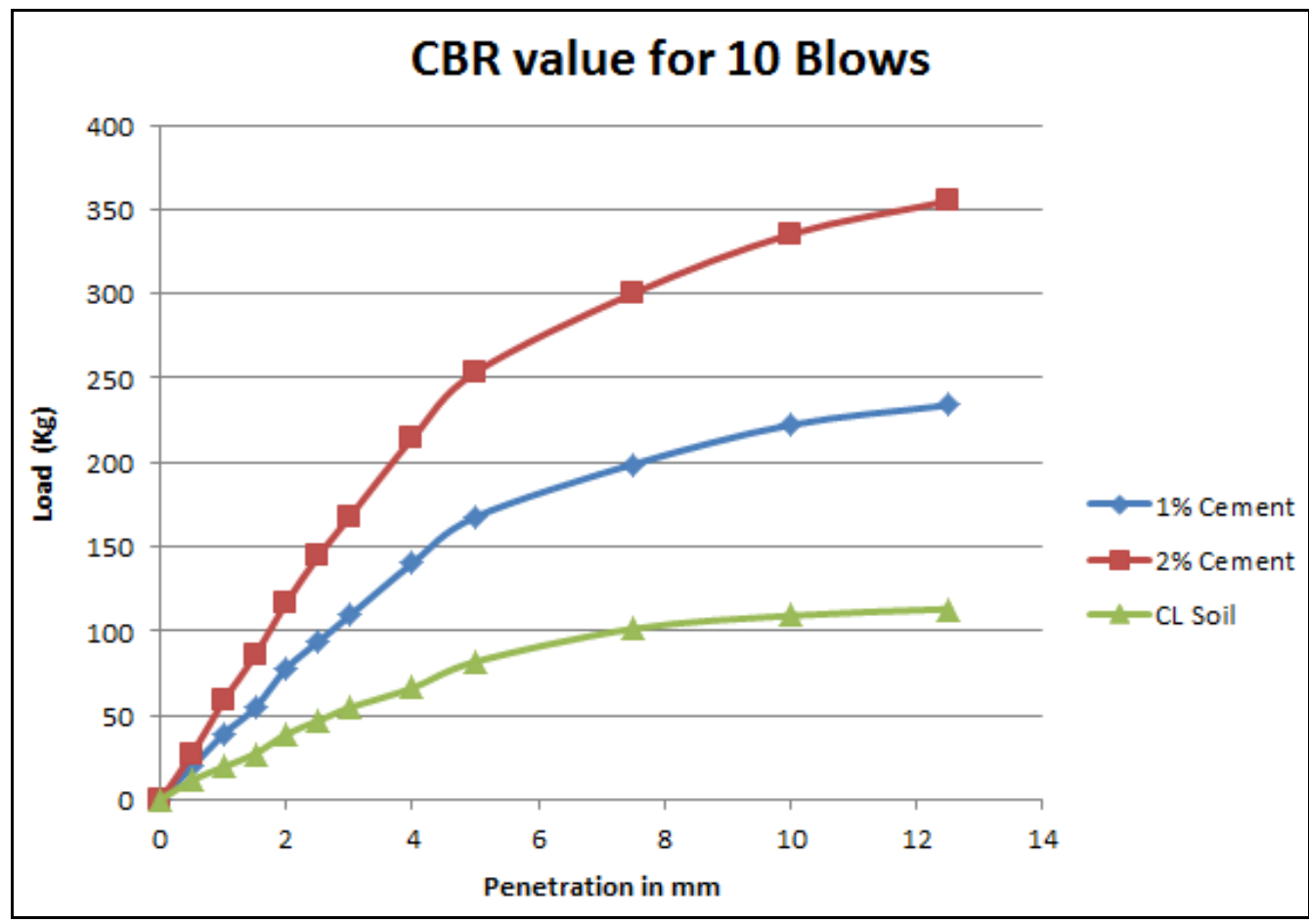

\begin{tabular}{|l|l|l|l|}
\hline \multicolumn{4}{|l|}{ CBR Value at St. Penetration $2.5 \mathrm{~mm}$ and St. load $1370 \mathrm{Kg}$} \\
\hline Sample & CL Soil & $1 \%$ & $2 \%$ \\
\hline Load at $2.5 \mathrm{~mm}$ & 46.8 & 93.6 & 144.3 \\
\hline CBR Value & 3.42 & 6.97 & 10.53 \\
\hline
\end{tabular}




\begin{tabular}{|l|l|l|l|}
\hline \multicolumn{4}{|l|}{ CBR Value at St. Penetration $5 \mathrm{~mm}$ and St. load $2055 \mathrm{Kg}$} \\
\hline Sample & CL Soil & $1 \%$ & $2 \%$ \\
\hline Load at $5 \mathrm{~mm}$ & 81.9 & 167.7 & 253.5 \\
\hline CBR Value & 3.99 & 8.16 & 12.34 \\
\hline
\end{tabular}

\subsubsection{CBR value for 30 Blows}

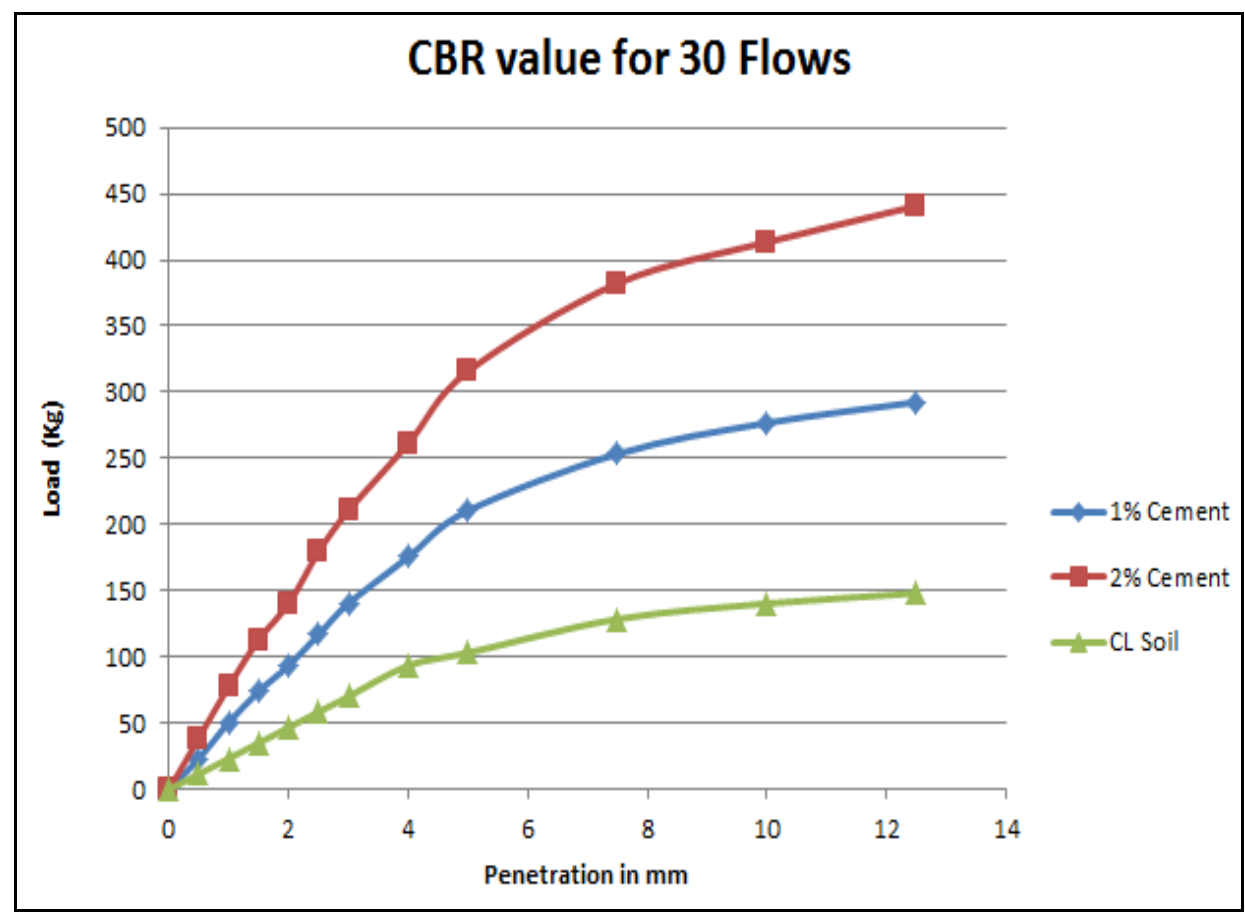

\begin{tabular}{|l|l|l|l|}
\hline \multicolumn{4}{|l|}{ CBR Value at St. Penetration $2.5 \mathrm{~mm}$ and St. load $1370 \mathrm{Kg}$} \\
\hline Sample & CL Soil & $1 \%$ & $2 \%$ \\
\hline Load at $2.5 \mathrm{~mm}$ & 58.5 & 117 & 179.40 \\
\hline CBR Value & 4.27 & 8.69 & 13.09 \\
\hline CBR Value at St. Penetration 5 mm and St. load $2055 \mathrm{Kg}$ \\
\hline Sample & CL Soil & $1 \%$ & $2 \%$ \\
\hline Load at $5 \mathrm{~mm}$ & 103.3 & 210.6 & 315.9 \\
\hline CBR Value & 5.12 & 10.24 & 15.37 \\
\hline
\end{tabular}




\subsubsection{CBR value for 65 Blows}

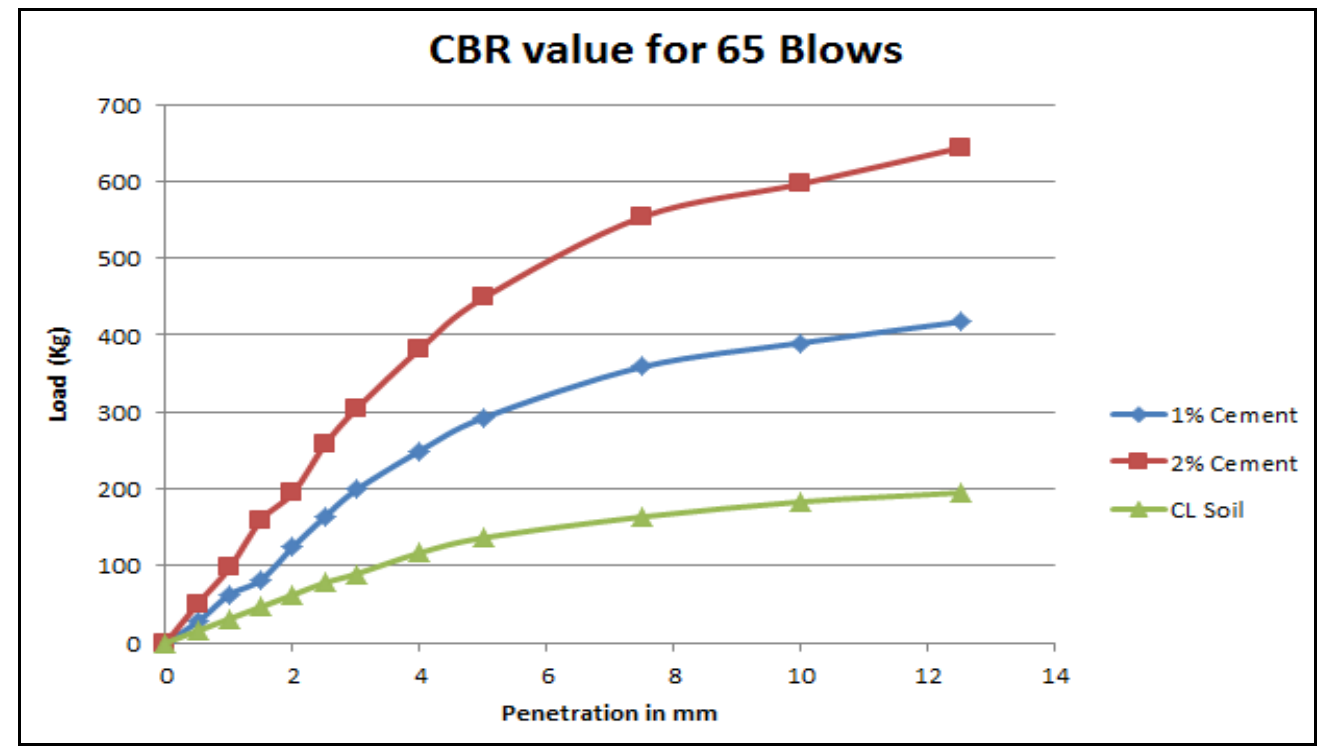

\begin{tabular}{|l|l|l|l|}
\hline \multicolumn{4}{|l|}{ CBR Value at St. Penetration $2.5 \mathrm{~mm}$ and St. load $1370 \mathrm{Kg}$} \\
\hline Sample & CL Soil & $1 \%$ & $2 \%$ \\
\hline Load at $2.5 \mathrm{~mm}$ & 78 & 163.8 & 257.40 \\
\hline CBR Value & 5.69 & 12.24 & 18.79 \\
\hline
\end{tabular}

\begin{tabular}{|l|l|l|l|}
\hline \multicolumn{4}{|l|}{ CBR Value at St. Penetration $5 \mathrm{~mm}$ and St. load $2055 \mathrm{Kg}$} \\
\hline Sample & CL Soil & $1 \%$ & $2 \%$ \\
\hline Load at $5 \mathrm{~mm}$ & 136.5 & 292.5 & 448.5 \\
\hline CBR Value & 6.64 & 14.23 & 21.83 \\
\hline
\end{tabular}

\subsubsection{CBR v/s Dry Density}

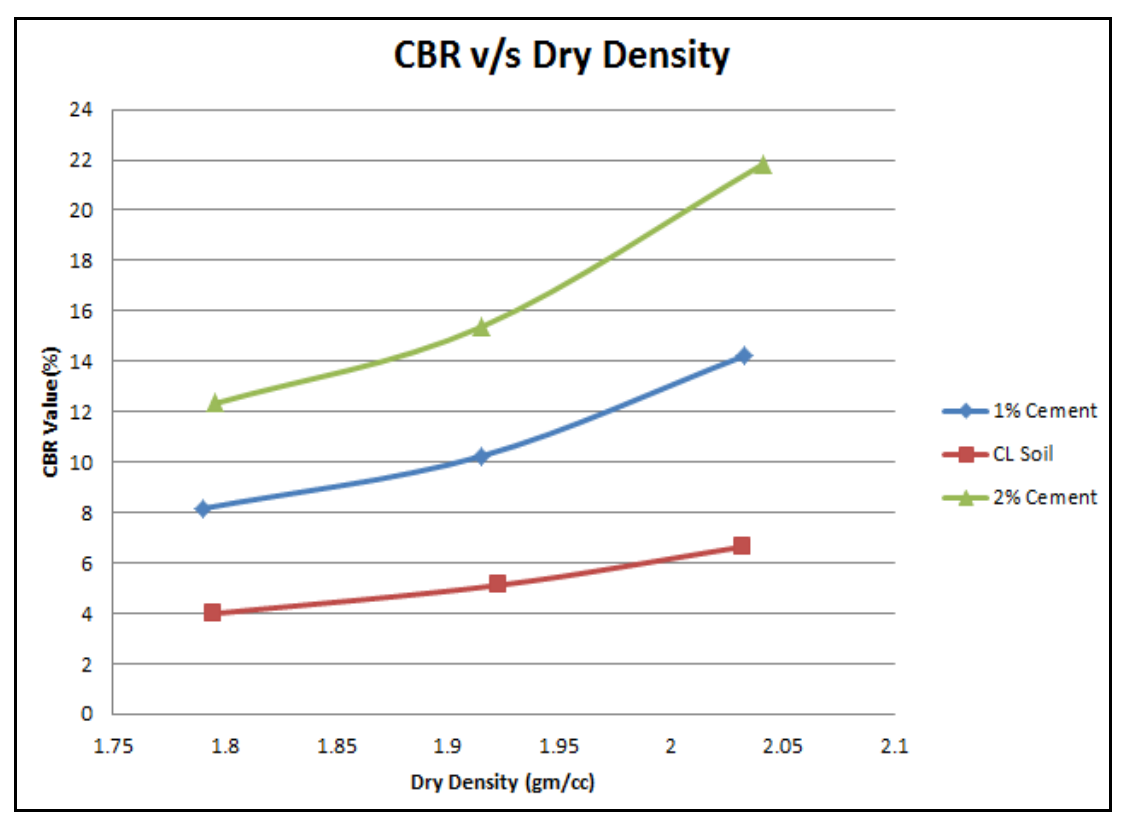

Maximum Dry Density of Soil is 2.052; here consider 97\% of Dry Density for determines the CBR value. 


\subsubsection{Comparative graph of CBR at 97\% MDD}

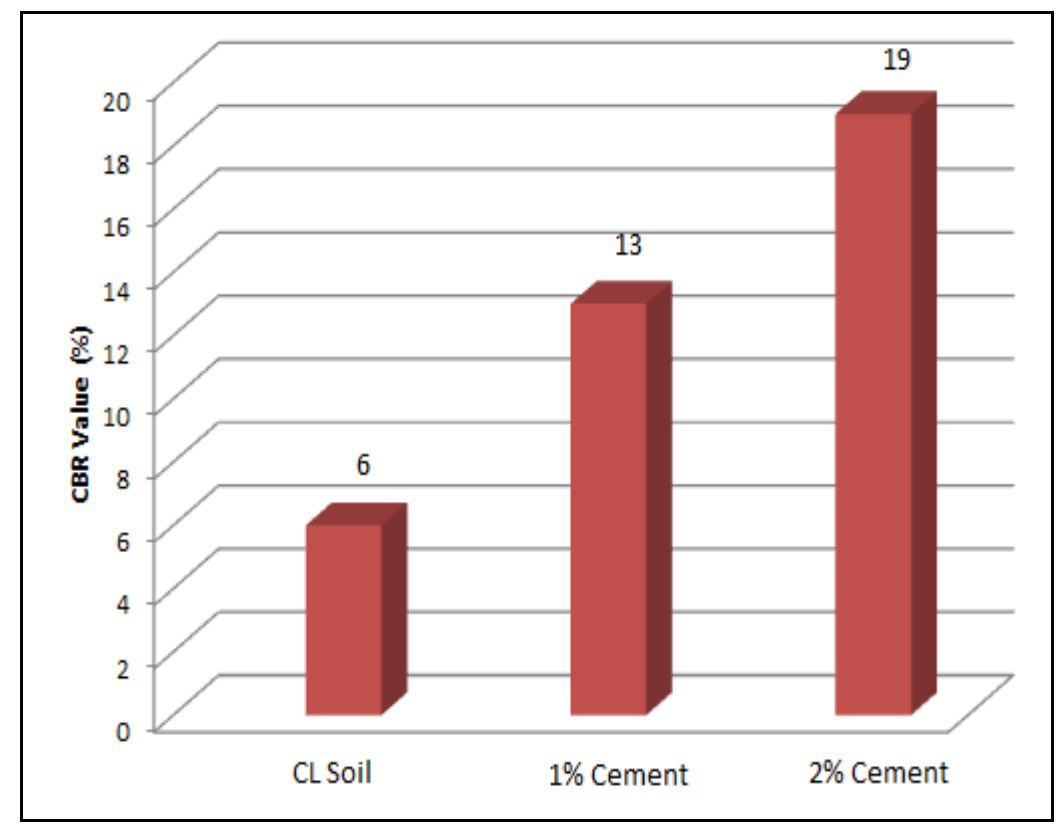

\section{CONCLUSION}

Proper field examinations, material recovery and research center blend plan methods are vital in guaranteeing the accomplishment of the methodology. These preparatory examinations conducted to stabilize the inorganic clay with low plasticity with $1 \%$ and $2 \%$ PPC help in giving essential data to quality control engineer a more sustainable approach to pavement construction. The accompanying key conclusions drawn after investigative examinations are:

Soil stabilization with PPC offers the pavement engineer an alternative to the traditional "remove and replace" strategies commonly utilized. The process not only offers the ability to enhance the engineering characteristics of an unsuitable soil, but also offers the engineer a more sustainable approach to pavement construction. It has been noted that fluid utmost declines and plastic limit of confinement qualities are declining yet the plasticity is diminishing contrasted and untreated soil. The increment in most extreme dry thickness is an after effect of flocculation and agglomeration of inorganic clay with low plasticity soil particles with PPC which is because of the consequence of beginning covering of soils by cement to structure bigger total, which thus possess bigger spaces.

Significant study conveys that CBR value of untreated CL soil and same treated with $1 \%$ and $2 \%$ PPC at 97\% MDD indicates the rise is more than 3 times compared to untreated soil. Also as percentage of cement is increased enhanced gain in CBR value is seen. CBR value obtained for $5 \mathrm{~mm}$ penetration needs to be taken for pavement design purpose.

The dynamic compaction characteristics is on a rising trend as number of blows increases with increasing in soil density and hence its strength and resistance to mechanical damage. It also reduces its water absorption.

\section{REFERENCES}

[1] A.C.S.V. Prasad, C.N.V. Satyanarayana Reddy, "The Potential of Cement Stabilized Gravelly Soils as Construction Material", Proceedings of Indian Geotechnical Conference December, 2011, Kochi.

[2] Christopher Holt (2010), "Chemical Stabilization of Inherently Weak Subgrade Soils for Road Construction - Applicability in Canada", Development of New Technologies for Classification of Materials Session of the Annual Conference of the Transportation Association of Canada Halifax, Nova Scotia.

[3] GrytanSarkar, Md. Rafiqul Islam, MuhammedAlamgir, Md. Rokonuzzaman (October 2012), "Study on the Geotechnical Properties of Cement based Composite Fine-grained Soil", International Journal of Advanced Structures and Geotechnical Engineering, ISSN 2319-5347, Vol. 01, No. 02

[4] IS: 2720 (Part II) - 1973, Determination of Water Content.

[5] IS: 2720 (Part IV) - 1985, Determination of Grain Size Analysis.

[6] IS: 2720 (Part V) - 1985, Determination of Liquid and Plastic Limit.

[7] IS: 2720 (Part VIII) - 1987, Determination of Water Content - Dry Density Relation Using Light Compaction.

[8] IS: 2720 (Part XVI) - 1997, Laboratory Determination of CBR.

[9] IS: 1498 - 1970, Classification and Identification of Soils for General Engineering Purposes.

[10] Mehdi Gharib, Hamidreza Saba, ArashBarazesh (2012), “An experimental study for identification and comparison of plastic index and shrinkage 
properties of clay soils with the addition of cement", European Journal of Experimental Biology.

[11] Mohammed Y. Fattah, Firas A. Salman and Bestun J. Nareeman (2010), "A treatment of expansive soil using different additives", ActaMontanisticaSlovaca.

[12] Sabry A. Shihata and Zaki A. Baghdadi (2001), "Long-term strength and durability of soil cement", JOURNAL OF MATERIALS IN CIVIL ENGINEERING / MAY/JUNE $2001 / \mathbf{1 6 1 - 1 6 5}$

[13] S. Bhuvaneshwari, R. G. Robinson, S. R. Gandhi (2005), "Stabilization of Expansive Soils Using Fly ash Fly Ash India", New Delhi.

[14] Y. Keerthi, P. DivyaKanthi, N. Shyam Chamberlin, B. Satyanarayana (April 2013), "Stabilization of Clayey Soil using Cement Kiln Waste", International Journal of Advanced Structures and Geotechnical Engineering ISSN 2319-5347, Vol. 02, No. 02. 